\title{
Personality Attitudes Affecting Employee Learning and Development: Prerequisites of Behaviour Leading to Learning and Development
}

\author{
DOI: 10.12776/QIP.V20I2.714
}

\author{
Lucie Vnoučková
}

Received 21 April 2016, Revised 17 June 2016, Accepted 08 October 2016

\begin{abstract}
Purpose: This study aims to reveal current approach and reactions of employees towards learning and development in organisations and to specify variants of behaviour as factors affecting employee development.
\end{abstract}

Methodology/Approach: The paper is based on evaluation of quantitative research. The sample contains 211 employees from organisations across sectors. Bivariate and multivariate statistical methods and analyses were used to lower the number of possible single approaches and practices.

Findings: Results identified and verified variants of employee reactions on organisational learning and development process and its impact on performance using quantitative data. Researched areas of employee behaviour variability are motivation, affect and performance. Outcomes show the main ways which are used by employees in order to pass the learning and development process.

Research Limitation/implication: The results may be used in practice to manage employee behaviour in order to grow constantly and use their potential talents and leaders. Besides this study there are several promising avenues for further research, i.e. the impact of within-person motivation on life-long development and the longer term impacts of learning in organisations.

Originality/Value of paper: This paper identyfies and describes variability of emoployee within-person behaviour during learning and development process. Employees react in five different directions (positive, negative or neutral as resignation). The impact on organisation is either positive or none.

Category: Case study

Keywords: education; development; performance; motivation; affect 


\section{INTRODUCTION}

Employee's behaviour during learning and development is a theme which is rarely studied. Every manager knows employee's behaviour varies over time, but this within-person variability is not well described, understood and sometimes is treated as error (Dalal, Bhave and Fiset, 2014). Therefore this study is focused on identification of a within-person approach to employee learning and development in organisations. The current extant theories of within-person variability converge on the contention that the process of organizational learning and development is dynamic rather than static. Day, Sin and Chen (2004) state that a considerable proportion of the variability in job behaviour is affected by within person rather than between-person sources. Although the benefits of understanding within-person variability in job behaviour are wide, there is a lack of clear knowledge about the systems and rules of types of employee behaviour. This paper defines various forms of variability and the various types of job behaviour during education and development in organisation.

The whole construct of within-person variability is very complex. Thus investigations in this area are useful because theorizing at the within-person level will provide a more scientific understanding of the process of variability of behaviour during employee education and development. On the other hand, it is important to note that within-person theorizing is usually frequently used in theory but empirical results are rare and do not differ because of their narrow focus (Dalal, Bhave and Fiset, 2014; Curran, Bauer, 2011; Beckmann, Wood and Minbashian, 2010).

Employee learning and development are truly crucial for organisational and economy development. But the process of learning and development is not constant. Variability of employee behaviour during organisational education and development is currently discussed theme; however there is a lack of studies and researches focused on this area. The aim is to reveal current approach and reactions of employees towards learning and development in organisations and to specify variants of behaviour as factors affecting employee development.

\subsection{Theoretical Background}

Current main goal of all organisations is to keep and develop quality employees (Ahsan, et al., 2013). It is obvious that the only thing that remains truly crucial in order to upgrade the organisations' and economy level are people and their management. Human resources and the ability of organisations of their management and development is irreplaceable in current knowledge economy (McDonnell, Lavelle and Gunnigle, 2014; Gururajan and Fink, 2010; Manning, 2010). Therefore, organisations should focus on education and learning process of each employee. It is necessary to monitor the process and reactions of employees on education and development with regard to their personality, kind of work, social values and behaviour - each employee is an individual with different perception and reactions (Loke, et al., 2012). Employees who are being 
educated and developed usually higher their interest in further development, they get to know the learning process and use of their abilities; they also learn how to manage and use their reactions to learning and development and how to continue in learning the process on a higher level. They also find how to use their new skills and knowledge to upgrade their performance. Employees who are constantly educated also work towards organisational goals and follow organisational strategy; they are communicative, cooperative, proactive, respectful, customer-friendly, willing and able to constantly learn $(\mathrm{Li}$, et al., 2009; Vnoučková, 2013). As Gururajan and Fink (2010) have stated, measuring the level of education and the process evaluation in organisations is necessary for predicting future development.

As stated by, among others, Ghiselli and Haire (1960), Dalal, Bhave and Fiset (2014) the validity of measuring both performance and prerequisites and motivation of employees is not constant, but varies cyclically with the classic course of the recurring rise and fall. Most researchers agree on the fact that the variability of behaviour and, consequently, performance or motivation is affected by interpersonal circumstances rather than by interpersonal relationships (Day, Sin and Chen, 2004; Glomb, et al. 2011).

In addition, authors Vancouver (2012), Vancouver, Thompson and Williams (2001) have found out in research that under various conditions the results of a single personality are different - may be positive, negative, or not anyhow affected. Research and meta-analysis of authors Sitzmann and Yeo (2013) has further concluded that the results and applicability of learning (output and efficiency) do not depend on the prerequisites for development, age (Young, et al., 2008) or satisfaction (Fisher, 2003; Judge, et al., 2001) (correlation 0.01), but rather on the relationship between prerequisites and past performances, by which an individual has already manifested prerequisites (correlation 0.32). Similarly, the correlation with the objectives is positive (Bandura, 1997; Judge, et al., 2001).

Changes in behaviour in terms of learning, development and application of their results in practice can be divided into short-term fluctuations with peaks and subsequent declines (cyclic partial changes without fundamentally measurable impacts), in the matter of days (Kanner, et al., 1981), and long-term changes, which are required for the development (Lord, et al., 2010), in the matter of years or more. What is desirable, therefore, is a change observable in the long run, which is experiencing an upward trend or standard-growing or stable level.

In theory, we can divide prerequisites and variability of behaviour into three main clusters: (1) theories emphasizing the role of ability, skills and knowledge, (2) theories focused on both the ability and motivation and (3) theories focusing only on motivation. These theories are based on the assumption that the outcome is a function of ability and motivation, whereby the ability is the possibility of performance and motivation is the willingness to generate performance (Blumberg and Pringle, 1982; Campbell, 1990). 
Individual theories provide insight from different perspectives. The result is, however, consistent with the rest of the presented theory, i.e., relations in the workplace and working environment, from which in its interaction conflicts arise are a key prerequisite for development. The change in learning and development is possible and measurable in a long-term horizon, when in a short time scale fluctuations occur that affect current approaches and effects. According to the prevailing impulses and trends in sinusoidal curve we can determine development or decline.

The submitted article is dedicated to the variability during learning and development of employees. Given the prerequisites set out in the theory it focuses predominantly on motivation, affect, and performance. These areas will be analysed using multivariate statistical methods for grouping of individual reactions of respondents to stimuli in education and development with the goal to describe the variability of their actions.

\section{METHODOLOGY}

The data were mainly extracted from secondary sources and analysis and discussion presented in the paper is linked to outcome synthesis and the evaluation of international research results. In order to capture all relevant studies, a variety of keywords for talent management, education, learning, attitudes towards learning process, motivation, performance and similar other ones were used. The research is descriptive and empirical in nature because the primary data were collected using the survey method through fact finding techniques such as questionnaire and interview.

The second part of this article analyses and evaluates the results of primary survey. The data for the evaluation of current education and learning in Czech organisations has been collected in primary quantitative survey by means of questionnaire investigation. Only one respondent per organisation was contacted. On behalf of the organisation, the questionnaire was completed by a respondent who holds a managerial position (has at least one direct subordinate). The data collection has respected the ethical aspects of research (Act No. 101/2000 Coll., on Personal Data Protection).

Questionnaires were completed by 211 employees in organisations across sectors. The method used for the collection of data was an electronic questionnaire that automatically recorded and pre-categorised respondents' answers (CAWI method) and telephonic interviewing (CATI method). The selection of a representative sample across sectors was carried out by selection of e-mail addresses and telephone numbers, which incorporates the advantages of multilevel random selection. The sample was selected solely for the purposes of the survey. The respondents were mainly (51\%) from small organisations (till 50 employees), $24 \%$ were from medium sized organisations and $25 \%$ from large organisations (over 250 employees). 
The questionnaires focused on the areas of organisational support (tangible and intangible rewards, mentoring, coaching, time to learn, constructive feedback), of education and learning, perception of support by employees, employee attitude toward education and learning, targets of education and learning and outcomes innovations, promotions, organisational growth and reactions of employees on education and learning The conclusiveness of the outputs and relationships obtained were supported by the tools of descriptive statistics; the analysis of correlation and multidimensional statistical methods were used to review the outcomes.

The data collection instrument included questions to measure the activities of employee learning and development in organisation. The questions were designed based on theories and similar researches driven by Gannon and Maher (2012), Dalal, Bhave and Fiset (2014), Day, Sin and Chen (2004), Glomb, et al. (2011), Vancouver (2012), Vancouver, Thompson and Williams (2001) and Sitzmann and Yeo (2013). Respondents' reactions to target statements and their attitudes to the given matter were restricted by offering a set of several statements. The questionnaire was also designed to contain items to measure social integration mechanisms. Additionally, Likert type scale was used. The extremes of the seven-point scale represented bipolar concepts of the evaluation dimension with verbal anchors in 1 (strongly disagree) and 7 (strongly agree). The scale permitted not only the specification of respondents' attitudes, but also their intensity. Answers of respondents were categorized according to identification questions that formed the first part of the questionnaire.

The level of dependence was measured based on correlation coefficient, using a scale devised by De Vaus (2002) and Field (2009). Validity of construct and its parts were tested by Cronbach Alpha. Further analyses were based on multidimensional statistical methods - factor analysis (varimax rotation; the Kaiser-Guttman rule was applied to select a group of significant factors. Following the recommendations of Anderson (2009), only determinants with an absolute value exceeding 0.3 were selected as significant for factor development; positive and negative dependency was further analysed in relation to its final benefits). Analyses formed valid factors, which influence and determine employee behaviour during organisational development.

\section{RESULTS}

The objective of this chapter is to evaluate the results obtained in the primary survey. The results of the quantitative research have been statistically evaluated and outputs have been formulated.

As stated in the theory, prerequisites and motivation of employees to learn and grow are not constant, but vary cyclically with the classic course of recurrent rise and fall. Variability in behaviour or motivation for behaviour (learning and development) is influenced by interpersonal circumstances. A prerequisite that is 
tested in the following subsections, i.e. that under various conditions the results of individual personalities are different, ensues from this.

Given the prerequisites defined in theory three main areas are tested: (1) The motivation for learning and development (2) affective perception and action, and (3) the performance provided. It is, therefore, an exploration of motivation (cause), affect (reaction), and performance (output) of education and development. These prerequisites should show the differences between the different approaches and variability in the behaviour of individuals within the education and development process.

\subsection{Motivation}

In the field of motivation approaches of employee to learning and development were tested. The areas that make them focus and that motivate them to learning and development were examined. Factor analysis was chosen to conduct the analysis. Similar styles of behaviour were sought during the monitored areas of education and development, describing stimulus and subsequent response that depends on the preferences of an individual, his inner values, goals and personal preferences. On the basis of these elements motivation of the groups of individuals and their responses to the set stimuli have been described. Identified factors helps to establish appropriate incentive mechanisms in the organization for encouraging sub-groups of employees to learning and development.

The analysis revealed four major categories of employee attitudes to learning and development, which explains 55\% of the total sample. Analysis grouped variables into factors in the composition shown in Table 1 below. Significant dependencies are marked in bold.

Table 1 - Factors found in the field of motivation

\begin{tabular}{|l|c|c|c|c|}
\hline \multirow{2}{*}{} & \multicolumn{4}{|c|}{ Factor } \\
\cline { 2 - 5 } & $\mathbf{1}$ & $\mathbf{2}$ & $\mathbf{3}$ & $\mathbf{4}$ \\
\hline Focus on future development & .015 & .085 & $\mathbf{. 7 0 2}$ & .012 \\
\hline Motivation to achieve something & -.019 & .138 & $\mathbf{. 6 2 3}$ & $\mathbf{. 5 6 2}$ \\
\hline Work in the area of interest & $\mathbf{. 6 9 4}$ & -.001 & -.019 & $\mathbf{. 3 2 7}$ \\
\hline $\begin{array}{l}\text { Comparison with the performance } \\
\text { of others }\end{array}$ & $\mathbf{. 4 9 1}$ & -.015 & $\mathbf{. 4 7 0}$ & .038 \\
\hline Focus of results on performance & $\mathbf{. 6 8 5}$ & .063 & .112 & -.129 \\
\hline $\begin{array}{l}\text { Development/learning is part of the } \\
\text { job }\end{array}$ & $\mathbf{. 5 7 1}$ & .283 & -.421 & .190 \\
\hline Rewards for education (tangible) & .089 & $\mathbf{. 8 9 1}$ & -.019 & .127 \\
\hline Incitement (intangible rewards) & .192 & $\mathbf{. 8 6 6}$ & .176 & -.093 \\
\hline Education benefits for themselves & .099 & -.008 & .042 & $\mathbf{. 8 7 3}$ \\
\hline Profit of education for organization & $\mathbf{. 5 6 9}$ & .346 & -.003 & .001 \\
\hline \% variance & 16.69 & 15.02 & 11.73 & 11.45 \\
\hline Name of factor & $\begin{array}{l}\text { Orientation on } \\
\text { organizational } \\
\text { development }\end{array}$ & $\begin{array}{c}\text { Orientation } \\
\text { on rewards }\end{array}$ & $\begin{array}{c}\text { Orientation } \\
\text { on future }\end{array}$ & $\begin{array}{c}\text { Orientation } \\
\text { on own } \\
\text { development }\end{array}$ \\
\hline
\end{tabular}

Source: Author's processing 
The first of the found factors explaining more than $15 \%$ of behaviour of the monitored employees. Incentives to encourage this kind of behaviour can be described as the orientation of employees on the development of the organization. According to the analysis results, they are very committed to the organization and have adopted its goals as if they were their own. They work in their own interest, they enjoy the work and are motivated to constantly develop and improve in the work process; their own progress is also a progress of an organization, which brings them satisfaction and motivates them to further achievements. In addition, they compare their performance with other individuals in the organization; they compare their benefits and compete among themselves which one of them will deliver greater benefits. Their learning and development, including further work activities are focused on performance. Through the growth of these employees the organization is growing accordingly. The organization is aware of this fact because in these cases learning and development is really a part of the job. Thus, the organization supports employees. At the same time, the monitored employees themselves stated that they develop because of the benefits for the organization. Both the organization and employee benefits from learning and development. This factor is very favourable for the organization; it concerns in the best sense of a word the Learning organization, having the right employees. The fact that the total of $16.69 \%$ of the monitored employees behaves like this is very positive.

The second factor found can be called Orientation on rewards; either tangible (salary / wages, benefits and other material benefits) or intangible (compliments, acknowledgement, recognition, advancement, promotions, etc.). This constitutes the main motivation of $15.02 \%$ of the monitored employees to develop. They will most likely not learn and develop without rewards; intrinsic motivation is low as regards these employees. They showed no interest in education, selfdevelopment, or development of organization. They are not interested in future orientation; they showed no relationship to work, colleagues, or performance.

The third factor explaining the behaviour of $12 \%$ of the reference sample of employees is focused and motivated with focus on the future, in which the employees see the positives of their current endeavour. However, they are strongly motivated to achieve something; it is not necessary to stimulate them from the outside. It is necessary, however, to show them an attractive future and the potential development that exists here. These employees are also motivated by the possibility of being compared with others, which drives them towards a set goal. Working with these employees is relatively easy if attractive goals are set for them (with them). The employees themselves want to fulfil them alone, without any further significant support of the organization.

The fourth factor shows the behaviour of employees depends on their motivation which is represented by the focus on learning and development, but only for themselves, not necessarily in relation to the organization. The factor can be called Orientation on own development. However, in the motivation to develop 
and be educated the organization plays a role, because these employees are indeed motivated to achieve something by themselves, but they also must (want) to work in their area of interest, i.e. if the field of activity is suitable, these employees (11.5\% of the monitored sample) are motivated to learn and develop, which has a positive impact on the organization. Moreover, the organization yet again does not have to make big efforts to motivate these employees, because they motivate themselves; they take learning and development as developing themselves and it motivates them to continue. It is, therefore, about talents or knowledge workers.

\subsection{Affect}

In the field of affective behaviour different perceptions and emotions were tested that were generated by employees during learning and development. Based on interviews employees were expressing their emotions and feelings, which their learning and development induces in them. These were then compared to the output values of education and development. The influence of effect on the output of the education and development process was monitored. Those areas were monitored that triggered a given behaviour (affect). For this analysis factor analysis was chosen again.

The analysis revealed five significant factors that characterize the affective behaviour of employees in learning and development. Factors explain the total of $61 \%$ of a sample. The analysis grouped variables into factors in the composition shown in Table 2 below. Significant dependencies are marked in bold.

Table 2 - Factors found in the field of affect

\begin{tabular}{|c|c|c|c|c|c|}
\hline & & & Factor & & \\
\hline & 1 & 2 & 3 & 4 & 5 \\
\hline Job orientation & -.035 & -.151 & .778 & -.159 & .024 \\
\hline Type of income & -.098 & .343 & .638 & .096 & -.230 \\
\hline Promotion & .287 & -.282 & .527 & .269 & .162 \\
\hline Entertaining & .007 & .625 & .060 & .480 & .258 \\
\hline Challenging & .763 & .080 & -.068 & .188 & .257 \\
\hline Motivating & -.045 & -.338 & .251 & .474 & -.473 \\
\hline Exhaustive & .827 & .137 & .019 & -.057 & -.218 \\
\hline Dull & -.004 & .029 & -.027 & .044 & .853 \\
\hline Stimulating & .220 & .808 & -.052 & -.091 & -.016 \\
\hline$\%$ variance & 12.94 & 12.78 & 12.51 & 11.83 & 11.07 \\
\hline Name of factor & $\begin{array}{c}\text { Challenging } \\
\text { process }\end{array}$ & $\begin{array}{l}\text { Stimulating } \\
\text { process }\end{array}$ & $\begin{array}{c}\text { Career } \\
\text { development }\end{array}$ & Entertainment & $\begin{array}{l}\text { Boredom } \\
\text { and } \\
\text { resistance }\end{array}$ \\
\hline Affectation & Surrender & Joy & Expectations & Entertainment & Resistance \\
\hline
\end{tabular}

Source: Author's processing

As can be seen from Table 2, response to learning and development is very different among groups of employees. With each group the upcoming learning causes different affective response. The analysis revealed five basic responses to 
learning and development. In the last row of the table a major affective response of the group is given.

In the first case, the learning and development is perceived as a difficult process that is also exhausting. This type of employees perceives education and development as an extra activity (compared to the usual working process), which makes them respond in terms of effect of defines against challenging activities. These employees do not directly resist learning and development; however, they consider them to be challenging. This kind of perception and affective response is typical for $13 \%$ of the monitored employees. Surrendering is a predominant affective response to learning and development.

The second factor grouped the monitored employees, for whom learning and development is stimulating, entertaining and, moreover, thanks to which they see the opportunity to distinguish themselves from others and get reward in addition to the form of a variable component depending on their changed abilities, or as a reward for the newly acquired skills or knowledge. These employees welcome learning and development, consider advantages of learning and development. They see learning as new activities, which will break them away from the stereotype and help them to move somewhere new. Total $13 \%$ of the reference sample behaves this way. Joy is the predominant affective response to learning and development.

The third factor characterizes employees who see positives in development in the possibility of obtaining an attractive position, career advancement, and better or variable income, depending on their activity and performance. They welcome learning and development as the possibility to improve their own abilities, they expect a positive future, to which they are looking forward. They accept learning and development pragmatically as a self-process and career development. This is how $12.5 \%$ of the reference sample sees development. Expectation is the predominant affective response to learning and development.

The fourth factor revealed a group of employees for whom learning and development is really motivating, they perceive it as fun. Expectations are really positive; these employees take educational and development activities as diversification, positive momentum and opportunity for active involvement. They never refuse opportunities offered for learning and development and use them to revive their workforce. $12 \%$ of employees behave in this manner. Entertainment is the predominant affective response to learning and development.

The fifth and last important factor found the opposite of the previous group. These employees show resentment to learning and development. They are bored by these activities; they do not want to be educated. They see no sense in education and development, nor aspire to higher positions or career development. They must be forced to education; they will not attempt to get involved in these activities. On the contrary, they argue that education and development demotivates them to work on the current job position in the organization. In this 
way, learning and development influences effect of $11 \%$ of the monitored employees. Resistance is the predominant affective reaction to learning and development.

It is appropriate to count with these attitudes and reactions of employees to more appropriately set a process of learning and development and appropriate approach to the group.

\subsection{Performance}

The performance was tested as an outcome of the process of learning, education and development. Testing was carried out on the basis of outputs from interviews of employees who should have expressed what the result of learning and development is. The analysis monitors impact of the educational process on the output of an individual. For the analysis, as in previous cases, the factor analysis was used.

The analysis has revealed four significant factors that characterize the output behaviour of employees from learning, education and development. Factors explain $60 \%$ of the sample. The analysis grouped variables into factors in the composition, which is shown in Table 3. Again, the significant dependence is in bold.

Table 3 - Factors found in the field of affect

\begin{tabular}{|l|c|c|c|c|}
\hline \multirow{2}{*}{} & \multicolumn{4}{|c|}{ Factor } \\
\cline { 2 - 5 } & $\mathbf{1}$ & $\mathbf{2}$ & $\mathbf{3}$ & $\mathbf{4}$ \\
\hline Job position & .025 & -.235 & .056 & $\mathbf{. 6 6 5}$ \\
\hline Type of income & -.004 & .205 & -.150 & $\mathbf{. 6 9 5}$ \\
\hline Promotion & -.214 & -.150 & .010 & $\mathbf{. 5 3 0}$ \\
\hline Excelling in tasks & -.066 & .052 & $\mathbf{. 7 5 4}$ & $\mathbf{- . 3 2 2}$ \\
\hline $\begin{array}{l}\text { Comparison with the performance of } \\
\text { others }\end{array}$ & .173 & .051 & $\mathbf{. 7 0 9}$ & .101 \\
\hline $\begin{array}{l}\text { Competition and awards for } \\
\text { performance }\end{array}$ & $\mathbf{. 5 4 8}$ & .142 & $\mathbf{. 4 8 4}$ & .214 \\
\hline Focus on performance results & .068 & $\mathbf{. 8 1 2}$ & .238 & -.084 \\
\hline Work on own projects & $\mathbf{. 4 5 3}$ & $\mathbf{. 4 8 5}$ & .086 & -.176 \\
\hline Feedback in the organization & $\mathbf{. 7 6 9}$ & .126 & -.027 & .021 \\
\hline Rewarding learning (tangible) & $\mathbf{. 8 3 2}$ & .077 & .128 & -.112 \\
\hline Motivation (intangible rewards) & $\mathbf{. 8 0 4}$ & .174 & .182 & -.136 \\
\hline Benefit for the organization & .235 & $\mathbf{. 7 8 6}$ & -.045 & -.013 \\
\hline \% variance & 22.77 & 15.14 & 11.32 & 11.16 \\
\hline Name of a factor & $\begin{array}{c}\text { Work in } \\
\text { organization }\end{array}$ & $\begin{array}{c}\text { Performance } \\
\text { in the project }\end{array}$ & $\begin{array}{c}\text { Focus on } \\
\text { performance }\end{array}$ & $\begin{array}{c}\text { Focus on } \\
\text { position }\end{array}$ \\
\hline
\end{tabular}

Source: Author's processing

As seen from the analysis, four different types of behaviour are the output of learning process. Learning and development are used either to improve employee outcomes in the job performance, or to enhance the performance in the projects; 
the third option is use of learning and development directly for improvement of the performance or focus on work in the desired position (promotion).

The first factor can be described as the output of learning and development in the form of application during the working process in the organization. This group of employees uses learning outcomes in competitions that appreciate their extra performance; they can, therefore, declare the gained new knowledge, skills or abilities. They work and utilize the results of education while working on projects; regarding the process and outcomes discussions are made, employees receive feedback and process and output are monitored and inspected. This is an appropriate approach of organizations that have an overview of how the process of learning and development works and what its outcomes are, where and how they are applicable. In connection with this the organization rewards the monitored process by both tangible and intangible rewards. It is, therefore, an educational and development process that is controlled mainly by the organization. It also emphasizes checking the results of the process and oversees that the outputs are incorporated into the work process. In this way, learning and development influence the final effect, i.e. the application of the results in $23 \%$ of the monitored employees.

The second factor brings together employees who focus on the application of learning and development results in the work on specific projects. The performance is, therefore, reflected in the project. The employees monitor during the process outputs in the form of benefits for their further specific activity. They are focused directly on performance; they are aware of the results that education brings and how they can be applied. At the same time, they argue that the benefit is especially obvious for the organization. They are educated in accordance with the objectives of the currently solved projects that need to be processed in the organization. It is a positive result of analysis for the organization that the employees in education and development focus on the performance and application of results in an organization. In this way, $15 \%$ of the monitored employees approach the results of learning and development.

The third factor puts together employees who are directly focused on performance, on their own output, which they want to compare with the performance of others; they love to compete and are rewarded for high performance. They use the outputs of the process of education and development to the maximum extent and want to excel. The monitored employees grouped in the given factor declare the ability to excel in tasks in relation to the learning and development. The process, therefore, has clear outcomes that employees use both in their own benefit and the benefit of the organization. Employees associated in this factor have an interest in education and development and use the results and declare the benefits of the process and its development. $11.3 \%$ of the monitored employees show these signs.

The fourth factor associates the employees who use the completed learning to obtain more positions, career development opportunities, and increase in 
remuneration. The output of the analysis, which states that these employees excel in tasks, leads to this assertion. They use learning and development only for their own benefit and for career advancement or obtaining the required (probably promised) position. These employees, therefore, use primarily learning and development programmes to declare they have passed rather than for the actual application of the performance results. The organization in this case probably educates employees in the desired positions, but the output process of learning and development is probably not controlled. Following the learning the given employees are automatically expected to have acquired new knowledge, abilities and skills and the output is not checked. While the organization supports the learning process, the results are merely formal, without any link to performance. $11 \%$ of the monitored employees show these signs.

\section{DISCUSSION}

Employees who participated at the research are willing to learn and are interested in such an opportunity. From the study of Lord, et al. (2010) it can also be concluded that employees generally appreciate the opportunities for development, education and learning and consider them an essential part of their work. This is good news for organizations because motivation of employees is generally high and it is, therefore, easier to work on education and learning of such personnel. Most authors also agree that motivation rather than interpersonal relationships influence interpersonal circumstances (Day, Sin and Chen, 2004; Glomb, et al. 2011). Almost the same results were achieved in relation to tangible rewards (rewards and benefits), as stated in the results of this article. Kumaraswamy, Chitale (2012) and Fiol and Lyles (1985) add that for the efficiency of the process the whole process needs to be intertwined in an organization.

Employee behaviour leading to performance is important to achieve the organization's goals (Campbell, 1990). Employee behaviour variability changes in the rank-ordering of employee performance scores over time. Therefore validities of predictor variables are welcome. This study now understood that these conceptualizations are the defining characteristics of within-person variability. It is therefore possible to define within-person variability simply as the change in an employee's performance level over time (see also Dalal, Bhave and Fiset, 2014).

Similar research by Dalal, Bhave and Fiset (2014) suggests the existence of considerable within-person variability. In a preliminary analysis of 36 independent samples from experience sampling studies in the workplace or classroom (total number of respondents $=4,785$ ) authors found that on average, $62 \%$ of the variability in task performance was connected to within-person sources. Metaanalysis made by Dalal and Hulin (2008) found considerable within-person variability in organizational citizenship behaviour (43\%), 
counterproductive work behaviour (49\%), proactive behaviour (39\%), creative behaviour (50\%), and overall job performance (64\%).

Most of the theoretical and scientific papers of organizational research neglected perspective of within-person performance variability or dismissed it as measurement error. Usually between-person worldview was studied. That made research questions simpler, and therefore so were theories, research designs, and statistical analyses (Dalal, Bhave and Fiset, 2014). By oversimplifying of the phenomenon of job behaviour variability the science was oversimplified as well. Thus the recommendations provided to practitioners were also oversimplified and useless. The goal of this study is to show some evidences that within-person variability plays an important role in this important, yet understudied, phenomenon. Yet, in the Czech or Slovak Republics, no similar researches were found.

The prospects of employees and organizations is seen in the work with social capital and understanding, developing and supporting relationships with others, as it can advance career and competitive success (Singh, et al., 2009). The paper examined the attitudes of employees and learning processes, education and development within the organization, i.e. how employees perceive support in area of learning and development in organizations, in which they are employed. The presented results and recommendations in response to identified weaknesses of other researches mentioned in the theory and discussion can be used in an organization of adult education, i.e. the employees' learning and development.

\section{CONCLUSION}

The results of research and analysis statistically reliably confirmed that the presented principles of employee learning and development are valid and important for development, education and management of talented employees. Resultant factors also clarify and support future aspirations of employees and organizational development.

The learning process most frequently goes through impulse in the form of employee orientation to the organization and its goals, or the rewards they obtain if they participate in learning and development. A reaction follows, which passes through the entire spectrum from joy to resistance. The application of increased performance while working on the job position or while working on projects then constitutes the result. Despite resistance from some employees the controlled process of learning and development that is embedded in the organization has the highest effect because all employees regardless of affects (reaction), through which they go, experience shift in learning and application of outputs. The efficiency of the learning process is then reached and it forces all employees to join in the process and to have clear and visible results.

The theory can be enriched by five affective reactions to learning and development. Employees on one hand welcome learning and development 
activities (entertainment), have positive emotions from it and perceive it as a new stimulus (joy), or use it for their future advancement (expectations); in other cases, education is perceived as a duty and necessity that interferes into daily activities and requires concentration (surrender), or learning and development even induces with employees' dislike, boredom and lack of motivation (resistance). It is appropriate to count with these attitudes and reactions of employees to set more appropriate process of learning and development and appropriate access to the group.

Four types of identifiers of learning behaviour were found to correct the practice of education. Learning and development are used either to improve labour outcomes in a particular job, or to enhance the performance within projects; the third option is to focus learning and development directly on the performance or focus on work in the desired position (promotion). As regards half of the observed sample of employees the education and development is also reflected in the results, i.e. in terms of increasing performance and its application. As to 23\% it is a process controlled by the organization, in other cases it is the self-interest of employees and their efforts to improve their performance. On the contrary, as to $11 \%$ of employees it is a purely formal process without any link to performance. Learning in organization is based on the reaction of employees when it comes to relationship to the external environment in the organization.

The results of the presented study may be recognized in other related researches focusing on within-person motivation and in an organization of adult education. Follow-up studies should determine the impact on lifelong learning and explore the long-term impact on learning within organizations. Additionally, presented results can be used in organisations to manage employee behaviour in learning and development process in order to positively influence the employee performance and consequently the performance of the whole organisation. Results also may be used in education process in higher education as case study in the area of human resource management.

\section{ACKNOWLEDGMENTS}

This contribution is a follow-up to the project of University of Economics and Management. 


\section{REFERENCES}

Ahsan, N., Fie, D.Y.G., Foong, Y.P. and Alam, S.S., 2013. Relationship between retention factors and affective organisational commitment among knowledge workers in Malaysia. Journal of Business Economics and Management, 14(5), pp.903-922.

Anderson, V., 2009. Research Methods in Human Resource Management. London: Chartered Institute of Personnel Development.

Bandura, A., 1997. Self-efficacy: The exercise of control. New York: Freeman.

Beckmann, N., Wood, R.E. and Minbashian, A., 2010. It depends how you look at it: On the relationship between neuroticism and conscientiousness at the within- and the between-person levels of analysis. Journal of Research in Personality, 44(5), pp.593-601.

Blumberg, M. \& Pringle, C. D., 1982. The missing opportunity in organizational research: Some implications for a theory of work performance. The Academy of Management Review, 7(4), pp.560-569.

Campbell, J.P., 1990. Modeling the performance prediction problem in industrial and organizational psychology. In: Dunnette, M.D., Hough, L.M. (Eds.), Handbook of industrial and organizational psychology. Vol 1 (2nd ed.). Palo Alto, CA: Consulting Psychologists Press, pp.687-732.

Curran, P.J. and Bauer, D.J., 2011. The disaggregation of within-person and between-person effects in longitudinal models of change. Annual Review of Psychology, 62, pp.583-619.

Dalal, R.S., Bhave, D.P. and Fiset, J., 2014. Within-Person Variability in Job Performance: A Theoretical Review and Research Agenda. Journal of Management, 40(5), pp.1396-1436. DOI: 10.1177/0149206314532691.

Dalal, R.S. and Hulin, C.L., 2008. Motivation for what? The criterion question. In: R. Kanfer, G. Chen, R. Pritchard (Eds.), Work motivation: Past, present and future, pp.63-100. New York, NY: Routledge.

Day, D.V., Sin, H.P. and Chen, T.T., 2004. Assessing the burdens of leadership: Effects of formal leadership roles on individual performance over time. Personnel Psychology, 57(3), pp.573-605.

De Vaus, D., 2002. Surveys in Social Research. London, UK: Routledge/Taylor and Francis.

Field, A., 2009. Discovering statistics using SPSS. 3rd ed. London: Sage.

Fiol, C.M. and Lyles, M.A., 1985. Organisational learning. The Academy of Management Review, 10(4), pp.803-813.

Fisher, C.D., 2003. Why do lay people believe that satisfaction and performance are correlated? Possible sources of a commonsense theory. Journal of Organizational Behavior, 24(6), pp.753-777. 
Gannon, J.M. and Maher, A., 2012. Developing tomorrow's talent: the case of an undergraduate mentoring programme. Education + Training, 54(6), pp.440-455.

Ghiselli, E.E. and Haire, M., 1960. The validation of selection tests in light of the dynamic nature of criteria. Personnel Psychology, 13(3), pp.225-231.

Glomb, T.M., Bhave, D.P., Miner, A.G. and Wall, M., 2011. Doing good, feeling good: Examining the role of organizational citizenship behaviors in changing mood. Personnel Psychology, 64(1), pp.191-223.

Gururajan, V. and Fink, D., 2010. Attitudes towards knowledge transfer in an environment to perform. Journal of Knowledge Management, 14(6), pp.828-840.

Judge, T.A., Thoresen, C.J., Bono, J.E. and Patton, G.K., 2001. The job satisfaction-job performance relationship: A qualitative and quantitative review. Psychological Bulletin, 127(3), pp.376-407.

Kanner, A.D., Coyne, J.C., Schaefer, C. and Lazarus, R.S., 1981. Comparisons of two modes of stress measurement: Daily hassles and uplifts versus major life events. Journal of Behavioral Medicine, 4(1), pp.1-39.

Kumaraswamy, K.S.N. and Chitale, C.M., 2012. Collaborative knowledge sharing strategy to enhance organisational learning. Journal of Management Development, 31(3), pp.308-322.

Li, J., Brake, G., Champion, A., Fuller, T., Gabel, S. and Hatcher-Busch, L., 2009. Workplace learning: the roles of knowledge accessibility and management. Journal of Workplace Learning, 21(4), pp.347-364.

Loke, S.P., Downe, A.,G., Sambasivan, M. and Khalid, K., 2012. A structural approach to integrating total quality management and knowledge management with supply chain learning. Journal of Business Economics and Management, 13(4), pp.776-800.

Lord, R.G., Diefendorff, J.M., Schmidt, A.M. and Hall, R.J., 2010. Selfregulation at work. Annual Review of Psychology, 61, pp.543-568.

Manning, P., 2010. Explaining and developing social capital for knowledge management purposes. Journal of Knowledge Management, 14(1), pp.83-99.

McDonnell, A., Lavelle, J. and Gunnigle, P., 2014. Human Resource Management in Multinational Enterprises: Evidence From a Late Industrializing Economy. Management International Review, 54(3), pp.361-380.

Singh, R., Ragins, B.R. and Tharenou, P., 2009. Who gets a mentor? A longitudinal assessment of the riding star hypothesis. Journal of Vocational Behavior, 74(1), pp.11-17.

Sitzmann, T. and Yeo, G., 2013. A meta-analytic investigation of the withinperson self-efficacy domain: Is selfefficacy a product of past performance or a driver of future performance? Personnel Psychology, 66(3), pp.531-568.

Vancouver, J.B., 2012. Rhetorical reckoning. Journal of Management, 38(2), pp.465-474. 
Vancouver, J.B., Thompson, C.M. and Williams, A.A., 2001. The changing signs in the relationships among self-efficacy, personal goals, and performance. Journal of Applied Psychology, 86(4), pp.605-620.

Vnoučková, L., 2013. Fluktuace a retence zaměstnanců [Employees Turnover and Retention]. Praha: Adart.

Young, B. W., Weir, P. L., Starkes, J. L. and Medic, N., 2008. Does lifelong learning temper age-related decline in sport performance? Interpreting differences between cross-sectional and longitudinal data. Experimental Aging Research, 34(1), pp.27-48.

\section{ABOUT THE AUTHOR}

Ing. Lucie Vnoučková, Ph.D. - is Assist. Professor of management at the University of Economics and Management, Department of Management, Czech Republic. Her research interests are related to human resources management and development, e-mail: lucie.vnouckova@vsem.cz, ORCID: http://orcid.org/00000003-4296-875X. 